\title{
23
}

\section{System modelling of ITEM: re-engineering of educational processes}

\author{
Harald Yndestad \\ Aalesund College \\ Fogd Grevesveg 9, 6009 Aalesund, Norway \\ e-mail: Harald.Yndestad@hials.no
}

\begin{abstract}
IT in educational management is not merely a technical problem, but to a large extent a matter of understanding what effect IT has on organisations. IT has a great potential for making better schools, but at the same time IT introduces structural instabilities. System modelling may help leaders to get a holistic view of IT in schools.
\end{abstract}

\section{Keywords}

Information technology, management, system theory, structural instability

\section{INTRODUCTION}

IT in Educational Management (ITEM) has grown over a period of at least twenty years. Initially ITEM was introduced to keep records of students and to control finances. During the last twenty years, IT has been taken widely in use. Few questioned the importance of ITEM or studied what consequences this new technology has on organisations. Today ITEM seems to grow most rapidly as an information system on Internet.

If we stop for a moment and ask the basic question: Why are we using IT in educational management? The answer will vary, depending on whether you are a student, a teacher, a financial director or a principal. Today there is a new generation of fast-growing information technology. Integration technologies such as CD-ROM, virtual reality and Internet will change the way we get and use information. As far as I know, there has not been much research on how this new generation of IT will effects schools. System theory is a useful concept for better understanding fundamental aspects of organisations. We hope system modelling will be a helpful tool of choosing an IT strategy. 


\section{SYSTEM VIEWS ON SCHOOLS}

\subsection{General system theory}

System theory is an organic view of understanding organisations (Bertalanffy, 1968). Systems are analysed with different perspectives in order to uncover different aspects of an organisation. Typical dual perspectives of systems are:

System $=$ Ontology + Knowledge Ontology $=$ Architecture + Dynamics Architecture $=$ Levels + Partners

\author{
Knowledge $=$ Ethic + Learning \\ Dynamics $=$ Structural + State \\ Partners $=$ Binding + Objects
}

Systems are analysed by dual elements and by levels of abstraction. Dynamics are studied by architecture and architecture by dynamics. Architecture is levels and partners. Partners are binding and objects. In system theory, the study of binding or relations between objects is of importance. By analysing the binding, we may know more about objects, architecture and the dynamics of organisations. In an organisation such as a school, binding between partners or objects is usually information. System theory should then be a suitable tool to analyse how a new generation of IT will effect schools as organisations.

\subsection{System architecture}

System architecture describes the relations between partners and levels of organisation. Level is an organisation that shares a common purpose. Partners are two or more organisations sharing a common purpose.

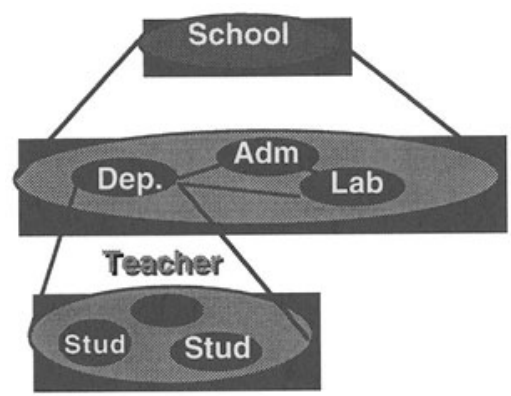

Figure 1 System internal partners
System partners in schools

Systems partners are partners because they are co-operating in sharing a common purpose. Sharing a common purpose needs some kind of binding between the partners. Typical internal binding in an organisation is communication, command, control and competence $\left(\mathrm{C}^{4}\right)$. In a school the situation is essentially the same. There is a need of communication, command, control and competence at each level of the organisation. This may be between students, teacher, administration and the external society.

IT is a tool for faster communication between organisations, command in scheduling, control of finances, control of student records and so on. Faster communication changes the binding between partners. Changes in binding will introduce changes in the organisation knowledge and dynamics. Faster information between the management, library, laboratory and so on, has made schools more flexible and efficient. On the other hand, the school has changed in the way it organised and solve its problems. From the theory of systems dynamics we know that this may lead to instability problems in the organisation (Forrester, 1967). 


\section{System levels in schools}

School usually have 3-5 organisational levels dependent on the type of school. We have the student level, the teacher level, the department level, the school and the governmental level. Since each organisation level has a special purpose, the different levels have different information needs. At a low organisation level the information focus is on the product, and at higher levels the focus is more on running the business. This means that even if all information in a school are carried on a single network, information must be adapted to each level. The teacher must be responsible for how to manage information in respect of teaching; the head of department must be responsible for the integration of information in his department, and so on.

The introduction of new IT such as Internet will radically change how the information is organised and distributed. Increase in information speed, relations and openness is equivalent to less binding between partners. Less binding between partners will expand the partners' purpose in the organisation. The effect of this is less specialised partners, a more decentralised organisation and fewer organisation levels. In schools we may expect that the management of students will be decentralised from a specialised student administration to an educational department and even to the teacher. The same effect will occur in relation to other parts of the organisation. The library is bypassed by direct search for information world-wide on the Internet. Integration of multimedia, simulation models, virtual reality and electronic instrumentation will open for a world-wide laboratory testing. This is a structural change of education processes. Such changes in education will undermine mass production of education and open for specialisation of education.

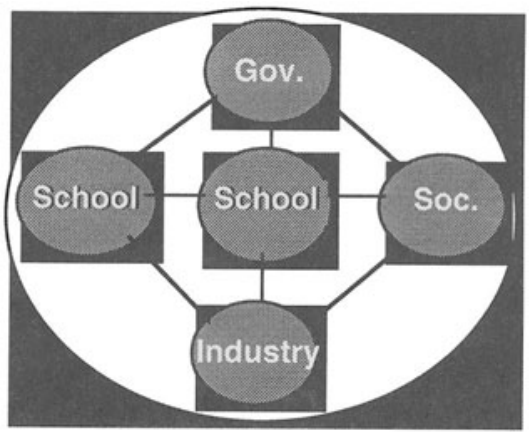

Figure 2 School and external partners

\section{External partners}

A school is related to external partners. This may be another school, the industry or other parts of the society. Together they are a system on a higher level sharing a common purpose. Fundamental aspects of systems are independent of system levels. Then changes in external binding, will have essentially the same effect as changing internal binding. IT already is in use through
the Internet for better
communication between schools and the society. The government is using IT for better student records. Students already seek information world-wide by Internet. Soon they will do this from their homes. This is an fantastic world-wide opportunity to get information online cheap and updated. But on the other hand: What is ITEM in a global campus?

\subsection{System Dynamics}

If there are no dynamics in an organisation, management is an easy task. System dynamics has two perspectives, viz state dynamics and structural dynamics. Management has to control both of these perspectives at the same time. Thus, from a management point of view, ITEM is using IT for better control of dynamics of schools as organisations. 


\section{State Dynamics}

State dynamics are the dynamics of partners based on stable relations. This is a well known paradigm from science and planning where the dynamics of organisation has a flow perspective. State dynamics provide a perspective where IT may easily be used. We may use IT to get an optimal estimate of future needs of recruitment, costs, teachers, employment of educated students and so on. Most schools are already using IT for optimising resources and this is probably the ITEM state of the art today.

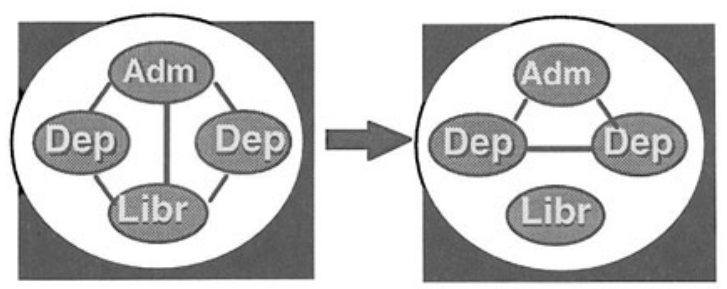

Figure 3 Structural dynamics

Structural dynamics refer to dynamic binding between partners. This is the same as changes in relations between partners. Structural dynamics have a relational perspective and thus we may discover the life cycle of objects. Examples of life cycles in schools are information, lectures, knowledge, staff and so on. ITEM is based on the ability to modulate the reality. There is no easy theory of understanding structural dynamics. The nearest is probably chaos theory and catastrophe theory (Zeeman, 1977). This type of dynamics is not controlled by IT but by management.

\section{A value theory}

The value of systems is judged by the strength of binding to its context. Structural dynamics thus is a critical problem leaders of schools should look out for.

\section{Total Quality Management of schools}

Schools need changes in a wanted direction like any other organisation. Understanding the importance of correct binding between partners is the key to influencing the direction. Analysing the relation between partners is essentially the same as the essence in Total Quality Management. Following this doctrine, an important management task is adapting the right relations between internal and external partners. The question is: How may we use IT for better relations with partners ?

A simple advice here is to follow the ISO 9004-2 standard for quality assurance of service organisations. In this standard schools are labelled as service organisations. Following the guidelines in the standard, we have a functional specification of ITEM. The standard will help us to select where to introduce IT inside schools and where to use IT in relation to external partners.

\subsection{System knowledge}

System knowledge is something more than the sum of knowledge for each individual person. Knowledge reflects the culture of the organisation. It affects how the organisation behaves, solves its problems and how it survives. The behaviour of the organisation affects the paper flow in the organisation, where the decision is taken and what information is used for decision making. Knowledge based ITEM is therefore not an automatic decision system. It is the ability to select the right IT-system and to predict how the introduction of IT will affect the organisation. 


\section{System ethics}

Systems as organisations have a tendency of striving for immortality (Heylighen, 1991). We know school lectures, courses, departments and even schools have a life cycle. The "genes" of schools are however in what they represent. Such "genes" materialise themselves in libraries, research papers, symbols and more. Today schools actively present their appearance and values on the Internet. This means that IT is the most important tool for accumulating historical information and to show the world its values. Thus the schools are moving their binding from local relations to more international relations. When most schools in the world are visible to each other on the Internet, this will have a dramatic effect on how these schools behave, how they define their identity and knowledge.

\section{System learning in schools}

System learning is the ability to predict, control and adapt the dynamics of the organisation. The dynamics of organisations are influenced by binding to internal and external partners. Binding between partners has a level perspective and a relational perspective. Learning organisations choose the right levels and relations. Traditionally schools have stable partners. Stable partners has open for schools as an stable organisation. The planning horizon has been 3 to 10 years. This is a typical state dynamic situation where ITEM may be used for prediction and control of recourses. The new generations of IT change the relation between internal and external partners. Learning in this perspective is choosing the right relation. This is the same as reengineering the organisation.

\section{Optimising resources}

Systems tends to optimise their energy and resources. Schools are hardly a profitable business in strict financial terms. Nevertheless there is the same need as in business organisations to optimise their resources. Optimising resources is not necessarily the same as doing things faster. Optimising resources may be doing the right thing, using the full potential of the organisation or adapting the organisation in new ways to its context. Introducing ITEM in organisations opens for a more flat and flexible organisation. Schools are no exception. By introduction IT schools may be more open, flexible and decentralised. The schools may then be better adapted to the society.

\subsection{Structural instability}

There is no question that most schools will take the opportunity to use IT to provide better education and improve their own functioning. But is IT always something positive for a school ? Is there a dark side of IT ? If we go back to a basic doctrine of systems, it tells us that the value of systems is dependent on binding to its context. It is obvious that IT rapidly makes new relations. If new loose relations grow faster than robust stable relations, the school may be isolated because it looses its binding to its context. In this case ITEM is not a tool which will make stable partners on a higher system level. It will be a tool for fragmentation of organisations or structural instability. In a rapid internationalisation process, this may be a price we have to pay.

\subsection{Education processes re-engineering}

If new generations of IT lead to structural instability, then IT will be more of a threat than a new opportunity. Such a threat may be solved by a re-engineering of the organisation as an education process. To reengineer an education process is to strive for a new kind of structural stability. This may by a closer vertical integration of schools in 
the value chain of education and it may be a closer integration between schools and the society.

\section{CONCLUSION}

New generations of IT such as CD-ROM, virtual reality and Internet will have a decisive influence on schools. Most schools will easily pick up the opportunity of using these new tools for cheaper and better education. At the same time this new generation of IT will introduce structural instabilities in schools as organisations. System theory is an holistic concept for understanding complex organisations. By using system theory we may be better prepared to understand how IT will influence schools and how to choose a right IT-strategy.

\section{REFERENCES}

Bertalanffy, L. (1968) General systems theory: foundations, development, applications. George Braziller, New York.

Forrester, J.W. (1967) Industrial dynamics. Productivity System Dynamics series. Portland, USA.

Heylighen, F. (1986) Towards a general framework for modelling representation changes, in Proceedings of the 11th International Congress on Cybernetics, Assoc. Internat. de Cyberne'tique, Namur.

Heylighen, F. (1991) An evolutionary system about evolutionary systems: introducing the Principia Cybernetica Project, in Workbook of the 1st Principia Cybernetica Workshop, (ed. F. Heylighen), Principia Cybernetica, Brussels-New York.

Senge, P. M. (1990) The Fifth Discipline. Century Business, UK.

Sterman, J.D. (1994) Modelling for learning organisations. Productivity Press, USA.

Yndestad, H. (1995) Generell Systemteori. HIA. [General System Theory, Aalesund College], Norway.

Zeeman, E.C. (1977) Catestrophe Theory: selected papers 1972-77. Addison-Wesley, Reading, Mass.

\section{BIOGRAPHY}

Harald Yndestad received has a degree in cybernetics from the University of Trondheim. He has worked for 10 years researching on complex IT systems, 6 years as principal at Aalesund College and 7 years as assistant professor at Aalesund College. For the last two years he has been engaged in research on IT and system theory. 